AIDS Care

Psychological and Socio-medical Aspects of AIDS/HIV

ISSN: 0954-0121 (Print) 1360-0451 (Online) Journal homepage: http://www.tandfonline.com/loi/caic20

\title{
Patterns of HIV and mental health service integration in New York State
}

\section{Sunhee Kim, Marc Ades, Veronica Pinho, Francine Cournos \& Karen McKinnon}

To cite this article: Sunhee Kim, Marc Ades, Veronica Pinho, Francine Cournos \& Karen McKinnon (2014) Patterns of HIV and mental health service integration in New York State, AIDS Care, 26:8, 1027-1031, DOI: 10.1080/09540121.2014.894613

To link to this article: http://dx.doi.org/10.1080/09540121.2014.894613

Published online: 12 Mar 2014.

Submit your article to this journal $\llbracket$

Џ Article views: 202

View related articles

View Crossmark data $\nearrow$

Citing articles: 1 View citing articles 


\title{
Patterns of HIV and mental health service integration in New York State
}

\author{
Sunhee Kim ${ }^{\mathrm{a}, \mathrm{b} *}$, Marc Ades ${ }^{\mathrm{b}, \mathrm{c}}$, Veronica Pinho ${ }^{\mathrm{a}, \mathrm{b}, \mathrm{c}}$, Francine Cournos ${ }^{\mathrm{b}, \mathrm{d}}$ and Karen McKinnon ${ }^{\mathrm{a}, \mathrm{b}, \mathrm{c}}$ \\ ${ }^{a}$ College of Physicians and Surgeons, Columbia University, New York, NY, USA; ${ }^{b}$ Research Foundation for Mental Hygiene, \\ New York, NY, USA; ${ }^{c}$ New York State Psychiatric Institute (NYSPI), Columbia University, New York, NY, USA; ${ }^{d}$ Mailman \\ School of Public Health, Columbia University New York, NY, USA
}

(Received 30 July 2013; accepted 11 February 2014)

\begin{abstract}
The Affordable Care Act (ACA) creates incentives to coordinate primary care, mental health (MH) care, and addiction services. Integration of clinical HIV and MH services has been shown to improve quality of life and physical and MH of people living with HIV/AIDS. However, few studies have investigated the practice of service integration systematically. We examined the practice patterns of 515 direct service providers in New York State who received training about HIV MH between May 2010 and July 2012. We sought to identify provider and treatment setting characteristics associated with an integrated spectrum of care. Using factor analysis and linear modeling, we found that patterns of service integration varied by type of health-care setting, service setting location, providers' HIV caseload, and the discipline of the provider describing the direct services. Understanding the existing capacities of clinicians providing care in a variety of settings throughout New York will help to guide staffing and linkage to enhance HIV MH service integration as significant shifts in the organization of health care occur.
\end{abstract}

Keywords: integrated care; practice patterns; provider roles; mental health; HIV

\section{Introduction}

In the USA, the Affordable Care Act (ACA) is creating historic new incentives to coordinate primary care, mental health $(\mathrm{MH})$ care, and addiction services previously lacking (Shim et al., 2012). HIV medicine has innovated such coordination, incorporating $\mathrm{MH}$ and addiction services within HIV care, resulting in improvements in quality of life and health of people living with HIV/AIDS (PLWH/A; Nebelkopf \& Penagos, 2005). HIV patients receiving integrated treatment services from infectious disease clinics showed reductions in psychiatric symptoms, emergency room visits and hospital stays, and a higher likelihood of receiving adequate psychotropic medication compared to those not receiving such services (Whetten et al., 2006). HIV patients receiving integrated medical and substance abuse treatment showed significant reductions in drug and alcohol use and improvements in $\mathrm{MH}$ and social functioning (Andersen et al., 2003; Proeschold-Bell, Heine, Pence, McAdam, \& Quinlivan, 2010), as well as reductions in viral load (Blank et al., 2011).

HIV MH service integration models most often cited in the US literature are the referral model, the consultationliaison model, and the multidisciplinary model (Dodds et al., 2004; Feingold \& Slammon, 1993). Funding from The Ryan White Care Act (RWCA) has allowed many US HIV clinics to provide $\mathrm{MH}$ care through a multidisciplinary model of integration, which decreases fragmentation of services by having $\mathrm{MH}$ and primary care providers share fully integrated responsibility for MH care (Kobayashi \& Standridge, 2000). However, there is considerable variation in how these models are applied (Dodds et al., 2004; Rasch et al., 2013), and it is not known to what extent integrated care is treatment as usual. The present investigation aims to describe care integration practices of providers who attended HIV MH trainings. We sought to identify provider and treatment setting characteristics associated with an integrated spectrum of care. We expected service integration to differ by type of service setting, geographic location, and receipt of RWCA funding.

\section{Methods}

Columbia HIV Mental Health Training conducted training for providers with majority HIV caseloads throughout New York State (NYS). Trainings lasting one to two hours addressed a wide array of topics at the intersection of HIV and $\mathrm{MH}$. Trainers tailored presentations to include relevant epidemiology, case material and discussion, and skillsbased interactive exercises. The New York State Psychiatric Institute (NYSPI) Review Board determined that eliciting voluntary, anonymous training feedback did not require approval as human subjects research.

\section{Data}

Evaluation was conducted with trainees between May 2010 and July 2012 using unique identifiers to ensure

\footnotetext{
*Corresponding author. Email: shk2125@columbia.edu 
Table 1. Participant and setting characteristics for each agency type.

\begin{tabular}{|c|c|c|c|c|c|c|c|c|c|c|c|}
\hline & & \multicolumn{2}{|c|}{ Hospital } & \multicolumn{2}{|c|}{$\mathrm{CBO}$} & \multicolumn{2}{|c|}{$\mathrm{CHC}$} & \multicolumn{2}{|c|}{$\begin{array}{c}\mathrm{MH} / \\
\text { substance } \\
\end{array}$} & \multicolumn{2}{|c|}{ Total } \\
\hline & & $n$ & $\%$ & $n$ & $\%$ & $n$ & $\%$ & $n$ & $\%$ & $n$ & $\%$ \\
\hline \multirow[t]{2}{*}{ Ryan White funded } & Yes & 146 & 94.80 & 218 & 89.30 & 59 & 100.00 & 52 & 88.10 & 475 & 92.2 \\
\hline & No & 8 & 5.20 & 26 & 10.70 & & & 7 & 11.90 & 41 & 8.0 \\
\hline \multirow[t]{3}{*}{ How many HIV/AIDS patients a month } & $1 \sim 10$ & 30 & 19.50 & 38 & 15.60 & 13 & 22.00 & 27 & 45.80 & 108 & 21.0 \\
\hline & $11 \sim 40$ & 62 & 40.30 & 148 & 60.70 & 21 & 35.60 & 25 & 42.40 & 256 & 49.7 \\
\hline & $41 \sim 100+$ & 62 & 40.30 & 58 & 23.80 & 25 & 42.40 & 7 & 11.90 & 152 & 29.5 \\
\hline \multirow[t]{3}{*}{ Primary employment setting location } & Rural & 5 & 3.2 & 11 & 4.5 & 3 & 5.1 & 3 & 5.1 & 22 & 4.3 \\
\hline & Suburban & 8 & 5.2 & 21 & 8.6 & 6 & 10.2 & 5 & 8.5 & 40 & 7.8 \\
\hline & Urban & 141 & 91.6 & 211 & 86.8 & 50 & 84.7 & 51 & 86.4 & 453 & 88.0 \\
\hline \multirow[t]{4}{*}{ Primary professional discipline } & MH providers & 28 & 18.2 & 16 & 6.6 & 4 & 6.8 & 11 & 18.6 & 59 & 11.5 \\
\hline & Medical providers & 15 & 9.7 & 7 & 2.9 & 13 & 22.0 & 5 & 8.5 & 40 & 7.8 \\
\hline & $\begin{array}{l}\text { Social Workers } \\
\text { (SWs) and Case } \\
\text { Managers (CMs) }\end{array}$ & 82 & 53.2 & 176 & 72.4 & 33 & 55.9 & 41 & 69.5 & 332 & 64.5 \\
\hline & Other & 29 & 18.8 & 45 & 18.5 & 9 & 15.3 & 2 & 3.4 & 85 & 16.5 \\
\hline \multirow[t]{2}{*}{ Years HIV/AIDS services } & 4 or less & 56 & 36.4 & 145 & 59.7 & 31 & 52.5 & 26 & 44.1 & 258 & 50.1 \\
\hline & 5 and more & 98 & 63.6 & 99 & 40.7 & 28 & 47.5 & 33 & 55.9 & 258 & 50.1 \\
\hline Total & & 154 & 29.9 & 243 & 47.2 & 59 & 11.5 & 59 & 11.5 & 515 & 100.0 \\
\hline
\end{tabular}

anonymity. Unique identifiers were assigned to trainees who did not provide them. Among participants who completed feedback forms $(N=2498)$, only the first set from those attending multiple trainings was used $(n=$ 1384); only participants who provided services directly to HIV/AIDS patients $(n=1094)$; and completed all outcome measures $(n=772)$ were included in our analysis. We obtained complete feedback on all variables of interest from 551 providers, excluding 36 who worked in atypical settings due to small numbers in each group. Our final sample was 515 providers (Table 1).

\section{Measures}

Participants reported their primary professional discipline, whether they provided direct services to patients, which services they currently provided, number of years they had provided such services, number of years working with HIV patients, the type of agency where they currently provided services, the agency's location, and whether the agency received RWCA funding. Disciplines were categorized as medical (physicians, physician assistants, registered nurses, nurse practitioners, advanced practice nurses, and pharmacists); MH (psychologists, psychiatrists, substance abuse professionals, and other MH workers); social workers/case managers; and other. Social workers were grouped with case managers because they might be providing either medical services or $\mathrm{MH}$ services or neither (e.g., concrete services such as benefit eligibility, housing). Participants' primary work settings were grouped into four categories: hospital/hospital clinic; community health center ( $\mathrm{CHC})$; $\mathrm{MH} /$ substance abuse setting; or community-based organization (CBO).

Participants selected from a list of seven choices the services they directly provided to patients (Table 2).

Table 2. Participant reports of services provided for each agency type.

\begin{tabular}{|c|c|c|c|c|c|c|c|c|c|c|}
\hline & \multicolumn{2}{|c|}{ Hospital } & \multicolumn{2}{|c|}{$\mathrm{CBO}$} & \multicolumn{2}{|c|}{$\mathrm{CHC}$} & \multicolumn{2}{|c|}{$\mathrm{MH} /$ substance } & \multicolumn{2}{|c|}{ Total } \\
\hline & $n$ & $\%$ & $n$ & $\%$ & $n$ & $\%$ & $n$ & $\%$ & $n$ & $\%$ \\
\hline Adherence counseling & 80 & 51.9 & 101 & 41.6 & 38 & 64.4 & 17 & 28.8 & 236 & 45.8 \\
\hline HIV medication management & 50 & 32.5 & 60 & 24.7 & 28 & 47.5 & 6 & 10.2 & 144 & 28.0 \\
\hline Resistance testing & 7 & 4.5 & 4 & 1.6 & 6 & 10.2 & 0 & 0.0 & 17 & 3.3 \\
\hline Screening for opportunistic infections (OIs) & 9 & 5.8 & 8 & 3.3 & 7 & 11.9 & 0 & 0.0 & 24 & 4.7 \\
\hline MH treatment therapy & 71 & 46.1 & 53 & 21.8 & 22 & 37.3 & 43 & 72.9 & 189 & 36.7 \\
\hline Neuropsychological/Neuropsychiatric management & 13 & 8.4 & 2 & 0.8 & 4 & 6.8 & 1 & 1.7 & 20 & 3.9 \\
\hline Psychiatric medication & 20 & 13.0 & 8 & 3.3 & 9 & 15.3 & 9 & 15.3 & 46 & 8.9 \\
\hline Total & 154 & & 243 & & 59 & & 59 & & 515 & \\
\hline
\end{tabular}




\section{Analysis}

Data were analyzed using IBM SPSS Statistics (Version $20)$ in two steps: factor analysis (FA) to explore $\mathrm{MH}$ and HIV services provided at participants' treatment settings and linear regression models to illustrate the effects of individual- and agency-relevant covariates.

We employed FA that estimates a factor for MH-HIV service integration based on the seven relevant services. We found a sufficient level of correlation (e.g., KaiserMeyer-Olkin Measure of Sampling Adequacy [KMO] larger than $0.5 ; 0.61)$ to support FA. Principal component analysis (without rotation) was used to extract factor loadings and the regression method was used to estimate factor scores.

The MH-HIV/AIDS service integration factor scores (of $z$-scores) were further investigated by linear regression models. Separate linear models for each agency type were conducted to examine provider service patterns in different settings. For each agency type, we included covariates in the model to show the effects of covariates on services: receipt of RWCA funding; number of HIVpositive patients seen in the last month; number of years working with HIV patients; employment location (urban, suburban and rural); and professional discipline.

\section{Results}

\section{MH-HIV service integration}

All seven direct services questions were reviewed by exploratory factor analysis to describe $\mathrm{MH}$ and HIV/ AIDS service provision. Three factors were extracted and labeled as MH-HIV/AIDS Integration, MH services, and HIV/AIDS services (Table 3).

\section{Factors relevant to MH-HIV service integration}

Linear regression models were applied to explore the effects of covariates on MH-HIV/AIDS service integration factor scores. Statistical significances of the associations were tested by Wald chi-square statistics (Table 4).

Different service integration patterns were seen in the four types of agencies, and significant associations were found:

\section{Hospitals/hospital clinics}

Participants from hospitals with large HIV caseloads delivered more-integrated HIV and MH service than those from hospitals with small HIV caseloads. Participants from hospitals in suburban and urban locations delivered more-integrated service than those in rural locations. Medical providers delivered more-integrated service than $\mathrm{MH}$ care providers.

\section{CBOs}

Medical providers delivered more-integrated service than MH care providers.

\section{CHCs}

Participants from CHCs with medium and large HIV caseloads delivered more-integrated service than those with small HIV caseloads. Medical providers delivered more-integrated service than $\mathrm{MH}$ providers.

\section{MH/substance settings}

Medical providers and the social worker/case manager group delivered more-integrated service than providers from MH disciplines.

Table 3. Factor loadings for MH and HIV/AIDS service integration.

Factor 1 (integration) Factor $2(\mathrm{MH}) \quad$ Factor 3 (HIV)

\begin{tabular}{llrrrr}
\hline What services do you currently provide? & & & \\
HIV/AIDS services & Adherence counseling & $\mathbf{0 . 5 6}$ & -0.06 & $\mathbf{0 . 6 2}$ \\
& HIV medication Management & $\mathbf{0 . 6 4}$ & -0.11 & $\mathbf{0 . 5 3}$ \\
& Resistance testing & $\mathbf{0 . 7 6}$ & -0.31 & $-\mathbf{0 . 4 4}$ \\
MH services & Screening for OIs & $\mathbf{0 . 7 4}$ & -0.39 & $-\mathbf{0 . 4 0}$ \\
& MH treatment therapy & 0.18 & $\mathbf{0 . 6 7}$ & -0.24 \\
& Neuropsychological/Neuropsychiatric management & $\mathbf{0 . 4 2}$ & $\mathbf{0 . 5 6}$ & -0.11 \\
& Psychiatric medication & $\mathbf{0 . 4 8}$ & $\mathbf{0 . 5 7}$ & 0.05 \\
\hline
\end{tabular}

Note: Factor loadings larger than 0.4 are in bold and explain the following latent factors.

Factor 1: All indicators except 'MH treatment/therapy' were heavily loaded on this factor, all with positive loading signs; these indicators can be explained as one latent variable, namely MH-HIV/AIDS service integration: a practitioner with a high integration factor score would be very likely to provide most of the six services.

Factor 2: All of the MH and none of the HIV/AIDS indicators loaded on this factor. These indicators can be seen as a latent variable of MH service specialization, and a practitioner with a high factor 2 score was more likely to provide MH services than HIV/AIDS services.

Factor 3: The factor loadings on HIV/AIDS indicators were high and at a similar level, but participants more likely to provide Adherence Counseling and HIV Medication Management were less likely to provide Resistance Testing and Screening for OIs, respectively. A practitioner with a high factor 3 score was more likely to provide HIV/AIDS services than MH services. 
Table 4. Effects of participant and setting characteristics on service integration.

\begin{tabular}{|c|c|c|c|c|c|}
\hline & & $\begin{array}{c}\text { Hospital } \\
B \text { (SE) }\end{array}$ & $\begin{array}{c}\mathrm{CBO} \\
B(\mathrm{SE})\end{array}$ & $\begin{array}{c}\mathrm{CHC} \\
B(\mathrm{SE})\end{array}$ & $\begin{array}{c}\mathrm{MH} / \text { substance } \\
B(\mathrm{SE})\end{array}$ \\
\hline \multicolumn{6}{|l|}{ Service integration } \\
\hline Intercept & & $-0.60(0.23)$ & $-0.40(0.20)$ & $-1.42(0.70)$ & $-0.73(0.21)$ \\
\hline \multirow[t]{2}{*}{ RWCA funded } & No & $0.68(0.46)$ & $-0.09(0.15)$ & NA & $-0.31(0.17)$ \\
\hline & Yes & 0 & 0 & 0 & 0 \\
\hline \multirow[t]{3}{*}{ HIV patients a month } & $41 \sim 100+$ & $0.48(0.23)^{*}$ & $0.22(0.16)$ & $1.28(0.35)^{* * *}$ & $0.32(0.28)$ \\
\hline & $11 \sim 40$ & $0.11(0.20)$ & $0.00(0.13)$ & $0.90(0.29)^{* *}$ & $0.24(0.16)$ \\
\hline & $<10$ & 0 & 0 & 0 & 0 \\
\hline \multirow[t]{3}{*}{ Employment location } & Suburban & $1.03(0.39)^{* *}$ & $0.18(0.20)$ & $0.12(0.71)$ & $-0.09(0.30)$ \\
\hline & Urban & $0.52(0.12)^{* * *}$ & $0.16(0.13)$ & $1.16(0.63)$ & $0.19(0.10)$ \\
\hline & Rural & 0 & 0 & 0 & 0 \\
\hline \multirow[t]{4}{*}{ Professional discipline } & Other & $-0.19(0.20)$ & $-0.11(0.16)$ & $0.29(0.59)$ & $-0.09(0.12)$ \\
\hline & $\mathrm{SW} / \mathrm{CM}$ & $-0.11(0.16)$ & $0.04(0.14)$ & $-0.40(0.40)$ & $0.32(0.12)^{* *}$ \\
\hline & Medical providers & $1.86(0.63)^{* *}$ & $2.14(0.77)^{* *}$ & $1.46(0.67)^{*}$ & $1.02(0.45)^{* *}$ \\
\hline & Mental health & 0 & 0 & 0 & 0 \\
\hline \multirow[t]{2}{*}{ HIV service years } & $5+$ years & $-0.06(0.12)$ & $0.00(0.10)$ & $0.08(0.30)$ & $-0.07(0.16)$ \\
\hline & $<5$ years & 0 & 0 & 0 & 0 \\
\hline
\end{tabular}

Notes: The coefficient $(B)$ refers to the adjusted mean difference of the integration factor score between the corresponding category (e.g., RWCA funded - No) and the reference category (e.g., RWCA funded - Yes).

The reference category for each variable (with the coefficient of 0 ) is as follows: RWCA funded, $<10$ patients for HIV patients a month, rural for employment location, $\mathrm{MH}$ providers for professional discipline, and $<5$ years for HIV service years.

The coefficients for intercepts indicate the estimated factor scores at the reference category.

${ }^{*} p<.05,{ }^{* *} p<.01$, and ${ }^{* * *} p<.001$.

\section{Discussion}

In the first study to examine patterns of HIV and MH care integration as practiced by health-care providers in NYS, we found that patterns of service integration varied by type of health-care setting, service setting location, provider's HIV caseload, and provider's discipline.

The vast majority of providers who attended trainings on HIV MH were working in medical settings rather than $\mathrm{MH}$ settings despite outreach to both types of settings. This pattern of self-selection may reflect a greater perceived need for training by medical providers or that the MH needs of people with HIV largely fall on medical settings or other factors that we did not study.

In all agency types we examined, medical providers were more likely to deliver integrated services than $\mathrm{MH}$ care providers. The current mobilization to integrate $\mathrm{MH}$ care into medical care rather than vice versa therefore appears to build upon existing capacities in NYS.

Almost all trainees were working in agencies receiving RWCA funds, limiting our ability to identify differences having such funding makes to care integration. Although ACA will extend Medicaid coverage to many previously uninsured PLWH/A and cover more services for $\mathrm{MH}$ and substance use, RWCA funds may remain essential for the completion of needed care. This will be very important to monitor as ACA is rolled out, especially if significant cuts to RWCA funds occur in the process.
Not surprisingly, providers working in hospitals with smaller HIV caseloads and those in rural settings appear to need more assistance in providing integrated $\mathrm{MH}$ HIV/AIDS care. Integration strategies such as phone consultation and/or telemedicine may be needed in these settings.

Only about $9 \%$ of participants were providing psychiatric medication. This may reflect which disciplines were most likely to attend HIV MH trainings, but it also raises the possibility that access to psychiatric medication is limited in many settings where patients with HIV infection are being treated. Trainees reported similarly low rates of neuropsychiatric management services.

The primary strength of our study was the opportunity to survey front-line practitioners seeking to meet the $\mathrm{MH}$ needs of PLWH/A. Clinicians or agencies receiving training may not be representative of all providers of $\mathrm{MH}$ services to PLWH/A, and we did not validate providers' reports of their practices. Not all participants completed evaluations and those who did not provide unique identifiers could have been counted more than once. We elicited broad categories of services not details of how services were delivered. Some social workers may have been $\mathrm{MH}$ care providers and therefore misclassified. Nonetheless our findings document patterns of service provision in New York's changing landscape of care integration that agencies and providers can draw 
upon to enhance staffing patterns and linkages to improve care integration for their patients.

\section{Funding}

This work was supported by the New York State Office of Mental Health, the New York State Department of Health AIDS Institute, and Health Research, Incorporated [grant number \#CO25661]. The content of this publication is solely the responsibility of the authors and does not necessarily represent the official views of the sponsors.

\section{References}

Andersen, M., Paliwoda, J., Kaczynski, R., Schoener, E., Harris, C., Madeja, C., ... Trent, C. (2003). Integrating medical and substance abuse treatment for addicts living with HIV/AIDS: Evidence based nursing practice model. The American Journal of Drug and Alcohol Abuse, 29, 847-859. doi:10.1081/ADA-120026264

Blank, M. B., Hanrahan, N. P., Fishbein, M., Wu, E. S., Tennille, J. A., Ten Have, T. R., ... Aiken, H. L. (2011). A randomized trial of a nursing intervention for HIV disease management among persons with serious mental illness. Psychiatric Services, 62, 1318-1324. doi:10.1176/ appi.ps.62.11.1318

Dodds, S., Nuehring, E. M., Blaney, N. T., Blakely, T., Lizzotte, J. M., Lopez, M., ... Sullivan, M. J. (2004). Integrating mental health services into primary HIV care for women: The whole life project. Public Health Reports, $119(1), 48-59$.

Feingold, A., \& Slammon, W. R. (1993). A model integrating mental health and primary care services for families with
HIV. General Hospital Psychiatry, 15, 290-300. doi:10.1016/0163-8343(93)90021-F

Kobayashi, J. S., \& Standridge, W. L. (2000). An integrated program for comprehensive HIV care. New Directions for Mental Health Services, 2000, 111-118. doi:10.1002/ yd.23320008715

Nebelkopf, E., \& Penagos, M. (2005). Holistic native network: Integrated HIV/AIDS, substance abuse, and mental health services for Native Americans in San Francisco. Journal of Psychoactive Drugs, 37, 257-264. doi:10.1080/02791072.2005.10400517

Proeschold-Bell, R. J., Heine, A., Pence, B. W., McAdam, K., \& Quinlivan, E. B. (2010). A cross-site, comparative effectiveness study of an integrated HIV and substance use treatment program. AIDS Patient Care \& STDs, 24, 651-658. doi:10.1089/apc.2010.0073

Rasch, R. F. R., Davidson, D., Seiters, J., MacMaster, S. A., Adams, S., Darby, K., \& Cooper, R. L. (2013). Integrated recovery management model for ex-offenders with cooccurring mental health and substance use disorders and high rates of HIV risk behaviors. Journal of the Association of Nurses in AIDS Care, 24, 438-448. doi:10.1016/j. jana.2012.08.006

Shim, R. S., Koplan, C., Langheim, F. J. P., Manseau, M., Oleskey, C., Powers, R. A., \& Compton, M. T. (2012). Health care reform and integrated care: A golden opportunity for preventive psychiatry. Psychiatric Services, 63, 1231-1233. doi:10.1176/appi.ps.201200072

Whetten, K., Reif, S., Ostermann, J., Pence, B. W., Swartz, M., Whetten, R., ... Eron, J. (2006). Improving health outcomes among individuals with HIV, mental illness, and substance use disorders in the Southeast [Supplemental material]. AIDS Care, 18, 18-26. doi:10.1080/09540120600839330 